\title{
STUDIES ON THE SOLUBLE ANTIGENS OF CLOSTRIDIUM OEDEMATIENS (CL. NOVYI)
}

\author{
J. M. Rutter* AND J. G. Collee \\ Department of Bacteriology, University Medical School, Edinburgh
}

\section{Plates XXX AND XXXI}

THE present method of typing Clostridium oedematiens is based on the various permutations of soluble antigens produced by different biotypes of the organism (Oakley, Warrack and Clarke, 1947; Oakley and Warrack, 1959). Oakley and his colleagues suggested that in-vitro neutralisation of the lecithovitellin reaction by specific $\mathrm{Cl}$. oedematiens antisera provides an adequate practical basis for the differentiation of the species into four types.

The term " lecithovitellin (LV) reaction" denotes the production of turbidity in extracts of egg-yolk emulsion after incubation with various agents; bacterial lecithinases (phospholipases) are frequently involved in the LV reaction and the soluble $\beta$ - and $\gamma$-antigens of $\mathrm{Cl}$. oedematiens have been characterised as haemolytic lecithinase- $\mathrm{C}$ enzymes (Macfarlane, 1948, 1950).

Oakley et al. stated that the LV test can be performed in tubes with concentrated culture products of $\mathrm{Cl}$. oedematiens or by a simultaneous culture and neutralisation procedure on egg-yolk agar plates. In practice it is found that strains of types B, C and D do not grow readily as surface cultures on agar media (Smith, 1955, p. 38; Willis and Hobbs, 1958), although the medium recently developed by Moore (1968) now merits attention. Moreover, results obtained in tube tests are not entirely satisfactory because some strains of Cl. oedematiens give weak and variable LV reactions (Keppie, 1944; Jamieson, 1949). The variable results may be partly attributable to the use of different culture media, and a standardised typing procedure would be helpful.

Macfarlane (1948) also showed that a lipase is present in culture products of type-A strains and this may be one of the LV factors $(\epsilon)$ described by Oakley $e t$ al. The picture was further complicated when Oakley and Warrack proposed that type-D strains and possibly type-B strains contain an LV factor $(\theta)$ that may be a lipase (see Macfarlane, 1950); this factor is antigenically distinct from the $\epsilon$-lipase of type-A strains. Thus, in mixtures of culture products of $\mathrm{Cl}$. oedematiens with egg-yolk emulsion, a positive LV reaction may be the result of (i) lecithinase, (ii) lipase, or (iii) both lecithinase and lipase activities. Type-A strains produce a haemolytic lecithinase $(\gamma)$ and a lipase $(\epsilon)$; strains of types B and D produce a haemolytic lecithinase $(\beta)$ and possibly a lipase $(\theta)$; the $\beta$ - and $\gamma$-lecithinases differ serologically. It is clear that simple observation of the LV reaction cannot differentiate between lecithinase and lipase activities, and recent developments in thin-layer chromatographic procedures for the investigation of lipids now allow a more detailed study of the factors involved.

Although the LV neutralisation test can be suitably poised to differentiate the $\beta$ - and $\gamma$-antigens, strains of types B and D produce antigenically identical lecithinases $(\beta)$. In order to confirm the identity of these strains it is necessary to demonstrate the $\alpha$-antigen; this lethal and dermonecrotic product is present only in culture filtrates of strains of types

Received 3 Feb. 1969; accepted 26 Apr. 1969.

* Present address: ARC Institute for Research on Animal Diseases, Compton, Berkshire.

J. MED. MICROBIOL.-VOL. 2 (1969) 
A and B (Oakley et al.) and it is the classical "lethal toxin" of $\mathrm{Cl}$. oedematiens. The nature and mode of action of the $\alpha$-antigen have not been determined, and at present there is no in-vitro test for its identification.

The work reported in the present paper was designed to examine some of the problems associated with typing $\mathrm{Cl}$. oedematiens, and the study was extended to differentiate the factors in culture products of $\mathrm{Cl}$. oedematiens that affect egg-yolk emulsion. The relationship of the $\alpha$-antigen to the cytopathic agent of $\mathrm{Cl}$. oedematiens (Veto, Backhausz and Horvath, 1957; Zemskov, 1964) was also investigated.

\section{MATERIALS AND METHODS}

Strains. Twenty strains of $\mathrm{Cl}$. oedematiens representative of types A, B, C and D, were kindly provided by $\mathrm{Mr}$ J. R. Hepple. A number of these strains originated from the NCTC; others were isolated at the Aberystwyth Veterinary Investigation Centre and some belonged to the Glaxo collection. In addition, 10 strains of $\mathrm{Cl}$. oedematiens were isolated from infected animal tissues kindly provided by Dr J. A. A. Watt of the Edinburgh Veterinary Investigation Centre. All of the above strains were lyophilised as soon as their purity and identity had been confirmed; thereafter, the strains were subcultured in cooked-meat broth and frequent checks of purity and identity were made.

Culture media. Cooked-meat broth (CMB) was used as a routine in the present study; nutrient broth (Oxoid Ltd, Southwark Bridge Rd, London S.E.1) replaced peptone infusion broth in the preparation of this medium (Cruickshank, 1965, p. 755). Standard meat infusion broth, horse flesh digest medium and peptone water were prepared as described by Cruickshank; sheep liver infusion broth was prepared with $500 \mathrm{~g}$ of fresh defatted sheep liver in place of lean meat. Brewer medium was prepared as described by Reed and Orr (1941); egg-yolk agar plates were prepared with 10 per cent. of sterile egg-yolk solution (Oxoid, or fresh egg-yolk solution, q.v.), and 0.1 per cent. of sodium thioglycollate was added to the medium on occasions. Fermentation test carbohydrate solutions were prepared as 10 per cent. solutions and sterilised by tyndallisation; an appropriate volume of each solution was added to the sterile basal medium in order to give a final concentration of 1 per cent. of the added substrate. Culture media were incubated as a routine at $37^{\circ} \mathrm{C}$ in anaerobic jars with a room-temperature catalyst (Baird and Tatlock Ltd, Chadwell Heath, Essex), and carbon dioxide (10 per cent.) was added to the anaerobic environment.

Saline. This was physiological saline, 0.85 per cent. $\mathrm{NaCl}$ in distilled water.

Calcium gelatin saline ("cagsal"). This solution was used extensively as a diluent; it consists of $227.5 \mathrm{ml}$ of 1 per cent. calcium chloride, $45 \mathrm{~g}$ of sodium chloride, $200 \mathrm{ml}$ of $5 \mathrm{per}$ cent. gelatin, and $5 \mathrm{~g}$ of phenol; the ingredients are made up to 5 litres with distilled water and sterilised by autoclaving at $10 \mathrm{lb}$. per sq. in. $\left(7 \mathrm{Mg}^{2}\right.$ per $\left.\mathrm{m}^{2}\right)$ pressure $\left(115^{\circ} \mathrm{C}\right)$ for $10 \mathrm{~min}$. (Brooks, Sterne and Warrack, 1957).

Buffers. A barbital sodium/sodium acetate/hydrochloric acid buffer developed by Michaelis (Michaelis, 1931, cited by Diem, 1962) was used at $p \mathrm{H} \mathrm{6.8.} \mathrm{Other} \mathrm{buffers} \mathrm{were}$ prepared as described by Cruickshank (p. 849).

Red cell suspensions. Citrated human group-O blood was obtained from the Blood Transfusion Department, Edinburgh Royal Infirmary, and was stored at $4^{\circ} \mathrm{C}$. A sample of blood was washed three times by centrifugation with physiological saline and the washed packed cells were made up as a 2 per cent. ( $\mathrm{v} / \mathrm{v})$ suspension in cagsal. The cell suspensions showed lysis after storage for about 4 days at $4^{\circ} \mathrm{C}$ and were then discarded. Suspensions of defibrinated horse blood (Wellcome Laboratories, Beckenham, Kent) and defibrinated sheep blood (Oxoid) were prepared in a similar manner.

Haemolysin $(H L)$ tests. Serial doubling dilutions of $0.5 \mathrm{ml}$ of test material were made in $3 \times \frac{1}{2}$ in. $(7 \cdot 6 \times 1.3 \mathrm{~cm})$ tubes with $0.5-\mathrm{ml}$ volumes of Michaelis buffer $(p \mathrm{H} \mathrm{6.8)}$. One volume $(0.5 \mathrm{ml})$ of the red cell suspension was added and the mixtures were shaken and then incubated in a waterbath at $37^{\circ} \mathrm{C}$; readings were made after $1 \mathrm{hr}$ and the tubes were then chilled overnight at $4^{\circ} \mathrm{C}$ before final estimates of haemolysis were made. The end-point was regarded 
as 25 per cent. haemolysis of the test mixtures; a control tube was prepared by a 4-fold dilution of a completely lysed test mixture and a visual comparison with the test series was made. A negative control mixture was included in each test. The haemolytic titre of culture products decreased as the substrate concentration increased from 1 to 10 per cent., and a 2 per cent. suspension of red cells was chosen for the present study.

Tests to demonstrate oxygen-labile haemolytic activity. These were performed as described by Gadalla (1965). Culture supernatants were oxidised with fresh hydrogen peroxide solution and subsequent reduction was achieved by adding a neutral solution of thioglycollic acid. Cultures of type-A strains were grown in CMB, CMB plus glucose, nutrient broth and glucose broth; red cells of man, horse and sheep were used as the substrates.

Lecithovitellin ( $L V)$ suspensions. The lecithovitellin substrate was either a commercially available egg-yolk emulsion (Oxoid) or a suspension prepared from a fresh egg-yolk in $250 \mathrm{ml}$ of borate-buffered saline at $p \mathrm{H} \mathrm{7 \cdot 3} \mathrm{(Sheldon,} \mathrm{Moskowitz} \mathrm{and} \mathrm{Deverell,} \mathrm{1959);} \mathrm{the} \mathrm{latter}$ emulsion was clarified by filtration through Whatman's no. 1 filter paper, sterilised by Seitz filtration and held at $-27^{\circ} \mathrm{C}$ until required for use.

Titration of factors that cause opalescence in egg-yolk emulsion. Serial doubling dilutions of $0.5 \mathrm{ml}$ of the test material were made in $0.5-\mathrm{ml}$ volumes of Michaelis buffer $(p \mathrm{H} 6 \cdot 8)$; one volume $(0.5 \mathrm{ml})$ of $\mathrm{LV}$ solution was added. The mixtures were shaken and then incubated for $1 \mathrm{hr}$ at $37^{\circ} \mathrm{C}$; readings were taken and the mixtures were chilled overnight at $4^{\circ} \mathrm{C}$ before final readings were made. The end-point was regarded as a slight opalescence when compared with a negative control mixture. A more definite end-point was obtained with fresh egg-yolk emulsion than with the commercial product, and a 10 per cent. dilution of the substrate in cagsal was rather more sensitive than undiluted emulsion. In subsequent tests, the LV substrate was prepared from fresh egg yolks and diluted 1 in 10 with cagsal. The procedure described by Oakley, Warrack and Clarke with $1-\mathrm{ml}$ volumes of undiluted test materials and undiluted LV solution was also used.

Neutralisation of haemolytic and LV activities. The test procedure developed during the present studies employed one volume $(0.5 \mathrm{ml})$ of a 1 in 2 dilution of the culture or culture supernatant in Michaelis buffer; antitoxin was added to the toxin to avoid the Danysz phenomenon. In tests with experimental antisera, 0.02 or $0.04 \mathrm{ml}$ of antitoxin was added to the test mixtures; these tests contained about 10 anti- $\gamma, 10$ anti- $\beta$ and 100 anti- $\beta$ units respectively. In tests with commercial antisera, the sera were diluted 1 in 50 in Michaelis buffer and this solution was used to dilute the culture supernatants 1 in 2 ; these tests contained $c .9$ anti- $\gamma$ or 5 anti- $\beta$ units respectively.

Thin-layer chromatography. Concentrated bacterial culture products (usually $0.5-\mathrm{ml}$ volumes) were held at $37^{\circ} \mathrm{C}$ with $1-\mathrm{ml}$ volumes of undiluted egg-yolk emulsion. The extraction procedure was similar to that described by Scrimgeour, Keane and Alder (1967); the total lipid was extracted from the reaction mixtures with $25 \mathrm{ml}$ of chloroform/methanol $(2: 1 \mathrm{v} / \mathrm{v})$ plus $5 \mathrm{ml}$ of $0.017 \mathrm{~N}$ sulphuric acid. The organic phase was removed and concentrated by evaporating to dryness in vacuo; the extracted lipid was resuspended in a small volume of chloroform. Glass plates $\left(9 \times 2 \frac{5}{8} \times \frac{1}{8}\right.$ in.; $\left.22.9 \times 6.7 \times 0.32 \mathrm{~cm}\right)$ were coated with a thin layer of silica gel G (Kieselgel G nach Stahl, E. Merck AG, supplied by Anderman and Co. Ltd, London) about $\frac{1}{32}$ in. $(0.08 \mathrm{~cm})$ in depth and spread by means of a metal spreading device.

The plates were activated for $60 \mathrm{~min}$. at $100^{\circ} \mathrm{C}$, then about $0.04 \mathrm{ml}$ of the lipid extract was loaded at one end of the plates in the form of a spot. After a few minutes, to allow air-drying, the plates were held vertically in an atmosphere saturated with a suitable solvent mixture. A small amount of glacial acetic acid was added to each solvent to avoid the formation of streaks and " tailing " of fatty acids. The solvents included cyclohexane:chloroform, 50:50 (Waldi, 1965); hexane:diethyl ether, 90:10 (Mangold, 1965); benzene:ether: ethanol:acetic acid, 50:40:2:0.2 (solvent system 1 of Freeman and West, 1966); chloroform: methanol:acetic acid:water, 65:25:8:4 (Nichols, 1964); and the double solvent system (ether:hexane, 35:65, followed by exposure to ammonia and final development in ether: methanol:ammonia, 84:14:2) described by Brockerhoff, Hoyle and Huang (1966). The plates were allowed to dry in air after removal from the solvent chamber and they were then 
held for 5-10 min. in a sealed jar with iodine crystals in order to locate the lipid components.

Standard preparations of lipids were kindly provided by Dr G. S. Boyd: these included lecithin, triglycerides (olive oil), cholesterol, cholesterol ester (cholesterol laurate and oleate), free fatty acids (oleic acid and lauric acid), and monoglycerides (glycerol monostearate). We were advised that impurities were present in most of these standards, but further purification was not attempted.

Demonstration of lethal activity. The soluble lethal factors in culture products were estimated by intravenous injection of $0 \cdot 1-\mathrm{ml}$ volumes of saline dilutions of the test material into male white mice of $c .20 \mathrm{~g}$. The results were recorded after $48 \mathrm{hr}$. Tests to demonstrate neutralisation of the soluble lethal factors were performed by allowing a suitable volume of antiserum to act on the test material for $30 \mathrm{~min}$. before $0.1-\mathrm{ml}$ volumes of the mixture were injected into mice.

Antitoxic sera. Three experimental antisera prepared against $\mathrm{Cl}$. oedematiens of types A, B and D were used in the present work; these sera were kindly gifted to one of us (J. G. C.) by Dr G. Harriet Warrack and their antitoxic potencies were known. Diagnostic type-A and type-B $\mathrm{Cl}$. oedematiens antisera were obtained from the Wellcome Laboratories; details of the antitoxic components of these sera were kindly provided by $\mathrm{Mr} \mathrm{H}$. B. G. Epps.

The preparation of concentrated culture products. Strains of $\mathrm{Cl}$. oedematiens were grown in 500-ml amounts of different culture media (see text), and the bacterial cells were removed by centrifugation at $6800 \mathrm{~g}$ for $60 \mathrm{~min}$. In some experiments the protein content of the culture supernatant was precipitated by adding the required amount of ammonium sulphate (Dixon and Webb, 1964); the precipitate was then collected and redissolved, dialysed against distilled water and concentrated with polyethylene glycol (M.W. 6000, Koch-Light Laboratories Ltd, Colnbrook, England). In other experiments, the culture supernatant was concentrated directly with polyethylene glycol. The $p \mathrm{H}$ was not controlled during these procedures, and the final $p \mathrm{H}$ of the concentrated products was about 6.0. Antibacterial agents (sodium azide 0.002 per cent., or " Hibitane", chlorhexidine, I.C.I. Ltd, Macclesfield, Cheshire, England, 0.002 per cent.) were frequently added to the concentrated products, which were held as a routine at $4^{\circ} \mathrm{C}$ or stored at $-27^{\circ} \mathrm{C}$.

Gel-filtration studies. Sephadex G-200 was used, and the column bed $(100 \times 2.7 \mathrm{~cm})$ was prepared as indicated by the manufacturers (Pharmacia G.B. Ltd, London, W.13). Phosphate-buffered saline $(p \mathrm{H} 6.8,0.02 \mathrm{M})$ was used as the eluting fluid and was fed to the column by gravity from a double reservoir system. The eluted material passed through a Uvicord monitoring apparatus (LKB Produkter, Stockholm, Sweden) and fractions were collected in $5 \times \frac{5}{8}$ in. $(12.7 \times 1.6 \mathrm{~cm})$ tubes in a Locarte fraction collector. Appropriate fractions were tested for biological activities.

Tissue-culture studies. Monolayers of chick-embryo fibroblasts were prepared from chopped, trypsinised 10-12-day-old chick embryos essentially according to the method of Dulbecco (1952); $1 \times 10^{6}$ cells in $1 \mathrm{ml}$ of growth medium were used for each tissue-culture tube so that rapid outgrowth occurred. The growth medium contained distilled water $75 \mathrm{ml}$, Eagle's tissue-culture medium (Wellcome) $10 \times$ strength, $8 \mathrm{ml}$, calf serum $5 \mathrm{ml}$, tryptose phosphate broth (Oxoid) $10 \mathrm{ml}, 4.4$ per cent. sodium bicarbonate $2 \mathrm{ml}$, penicillin $100 \mathrm{IU}$ per ml, streptomycin sulphate $100 \mu \mathrm{g}$ per ml, and Mycostatin $25 \mu \mathrm{g}$ per ml. The tubes of tissue cells were held horizontally for about $24 \mathrm{hr}$ at $37^{\circ} \mathrm{C}$ to allow cell adhesion. The medium was then replaced with maintenance medium in which the calf serum component was reduced to $2 \mathrm{ml}$ and the bicarbonate solution was increased to $3 \mathrm{ml}$ in the above recipe. The cytopathic activity of test materials was assessed by adding $0.1 \mathrm{ml}$ of appropriate dilutions of the test material in saline to the monolayers; immediately before cytopathic tests, the maintenance medium in each tube was replaced with $0.9 \mathrm{ml}$ of fresh maintenance medium. The test monolayers were rolled at $37^{\circ} \mathrm{C}$ and a cytopathic effect became obvious after overnight incubation. Tests to demonstrate neutralisation of the cytopathic factors were performed by allowing a suitable volume of antiserum to act on the test material for $30 \mathrm{~min}$. before $0 \cdot 1 \mathrm{ml}$ of the mixture was added to the tissue-culture tubes.

Baby hamster kidney (BHK) cells (MacPherson and Stoker, 1962) were obtained from the Animal Disease Research Institute, Moredun, Edinburgh, and were propagated in Eagle's 
medium. Monkey kidney (MK) cells were obtained from the MRC Laboratory, Holly Hill, London, and were propagated in " 199 " medium (Cruickshank, p. 1029). Monolayers of these cells were kindly provided by the Virology Unit of this Department.

\section{RESULTS}

\section{The $\mathrm{LV}$ and haemolytic activities of $\mathrm{Cl}$. oedematiens}

\section{Problems encountered in the LV test system}

It soon became clear that a cooked-meat broth medium (CMB) supports consistently reliable growth of all types of $\mathrm{Cl}$. oedematiens. Strains of types $\mathrm{B}, \mathrm{C}$ and $\mathrm{D}$ do not grow readily in tubes of nutrient broth, peptone water, meat infusion broth and horse-flesh digest broth, and growth was not regularly successful in a semi-solid Brewer medium. Luxuriant growth was obtained in tubes of a sheep-liver infusion broth, but the advantage was offset by the variable production of soluble antigens in this medium. Accordingly, centrifuged unconcentrated CMB culture supernatants were used as the source of biologically active material in the present study unless otherwise stated in the text.

In preliminary experiments performed with culture products of $\mathrm{Cl}$. oedematiens, a suitable LV test system (see Methods) was defined: a volume of culture supernatant diluted with an equal volume of Michaelis buffer $(p \mathrm{H} \mathrm{6.8)}$ is mixed with lecithovitellin solution diluted 1 in 10 with cagsal; the mixture is incubated in a waterbath for $1 \mathrm{hr}$ at $37^{\circ} \mathrm{C}$ and then held overnight at $4^{\circ} \mathrm{C}$ before final readings are made. A positive $L V$ reaction is denoted by an opalescence or turbidity in the reaction mixture.

Strains of $\mathrm{Cl}$. oedematiens of types $\mathrm{A}$ and $\mathrm{D}$ give a positive $\mathrm{LV}$ reaction in the test system, but type-B strains frequently give a negative LV reaction. Culture supernatants of a type-B strain grown for 1, 2 and 5 days in 100-ml amounts of nutrient broth, meat infusion broth and horse-flesh digest broth, or in CMB with added glucose, maltose, mannose, fructose, inositol, glycerol, lactose or sucrose, also gave negative LV reactions. The conditions of the LV test were varied by (i) increasing the incubation period at $37^{\circ} \mathrm{C}$ to $4 \mathrm{hr}$, and (ii) using undiluted LV solution instead of diluted emulsion, but some type-B strains still failed to give a positive LV reaction. An LV factor was regularly detectable when type-B cultures in $\mathrm{CMB}$, nutrient broth or infusion broth were concentrated $50-100$-fold, but it is clear that unconcentrated cultures of these strains do not contain consistently adequate amounts of the $\beta$-antigen to produce a demonstrable reaction in the LV test system.

Considerable difficulties were also encountered when culture and neutralisation tests were performed on egg-yolk agar plates. Type-A strains of $\mathrm{Cl}$. oedematiens grew readily as surface cultures, but growth was frequently inhibited in the area that was spread with antitoxin; this is probably attributable to the preservative $(0.35$ per cent. cresol) in commercially available antitoxin. In addition, the spreading confluent growth that occurs with many strains of $C l$. oedematiens obscures the neutralisation pattern on half-antitoxin agar plates. Strains of types B, C and D usually failed to grow on egg-yolk agar plates.

On the basis of these results, the LV tube test is not entirely satisfactory for 
the identification of $\mathrm{Cl}$. oedematiens and the typing of unknown strains on solid indicator media is inadvisable. The lecithinase enzymes of this organism are also haemolytic, thus, the haemolytic reactions of culture products were investigated with a view to exploiting these in the typing system.

\section{The sensitivity of red cells of different species to the haemolytic} effect of $\mathrm{Cl}$. oedematiens culture products

Preliminary experiments were performed with concentrated culture fractions prepared from $\mathrm{CMB}$ cultures of $\mathrm{Cl}$. oedematiens strains representative of types A, B and D. The type-C strain did not produce detectable haemolysin in CMB medium, although haemolytic activity was noted in certain cultures of this strain (q.v.). The results obtained with the test strains of types A, B and D (table I) show clearly that human red cells are more sensitive than the red cells

TABLE I

The haemolytic activities of different culture concentrates of $\mathrm{Cl}$. oedematiens determined with three species of red cell

\begin{tabular}{c|c|c|c}
\hline \multirow{2}{*}{$\begin{array}{c}\text { Strain of } C l \text { oedematiens } \\
\text { that produced the test } \\
\text { culture concentrate }\end{array}$} & \multicolumn{2}{|c}{$\begin{array}{c}\text { Maximal dilutions at which prompt and delayed haemolytic } \\
\text { activities were demonstrable in tests with }\end{array}$} \\
\cline { 2 - 4 } & human red cells & horse red cells & sheep red cells \\
\hline GR1A & $320^{*} / 640$ & $160 / 160$ & $10 / 80$ \\
GR2A & $80 / 160$ & $10 / 20$ & $<10 / 10$ \\
GR1B & $320 / 1280$ & $<10 / 40$ & $20 / 160$ \\
GR1D & $1280 / 10,240$ & $20 / 2560$ & $10 / 5120$ \\
& & & \\
\hline
\end{tabular}

* The first reading was taken immediately after the incubation period of $1 \mathrm{hr}$ at $37^{\circ} \mathrm{C}$; the second reading was made after overnight cooling at $4^{\circ} \mathrm{C}$ to detect any hot-cold haemolytic effect. The figures are the maximum final dilutions of the culture products that caused 25 per cent. of visible haemolysis.

of horse or sheep to the haemolytic products of all types of $\mathrm{Cl}$. oedematiens. Human cells do not exhibit a marked hot-cold lysis effect and thus provide more definite results after $1 \mathrm{hr}$ at $37^{\circ} \mathrm{C}$. For these reasons, human cells ( 2 per cent. $\mathrm{v} / \mathrm{v}$ diluted in cagsal) were used in the haemolytic test system.

\section{Comparison of the haemolytic and LV test systems}

The results of comparative experiments performed with unconcentrated culture supernatants prepared from 19 strains of $\mathrm{Cl}$. oedematiens of types A, $\mathrm{B}, \mathrm{C}$ and $\mathrm{D}$ grown in $\mathrm{CMB}$ medium and tested with experimental antisera (see Methods) are given in table II. The results obtained with these strains in the haemolytic control tests are consistently positive, with the anticipated exception of the type-C strain which produces no haemolysin or LV factor in CMB medium. The haemolysin test system is much more sensitive than the LV test system, and this is of special advantage in typing type-B strains, which 


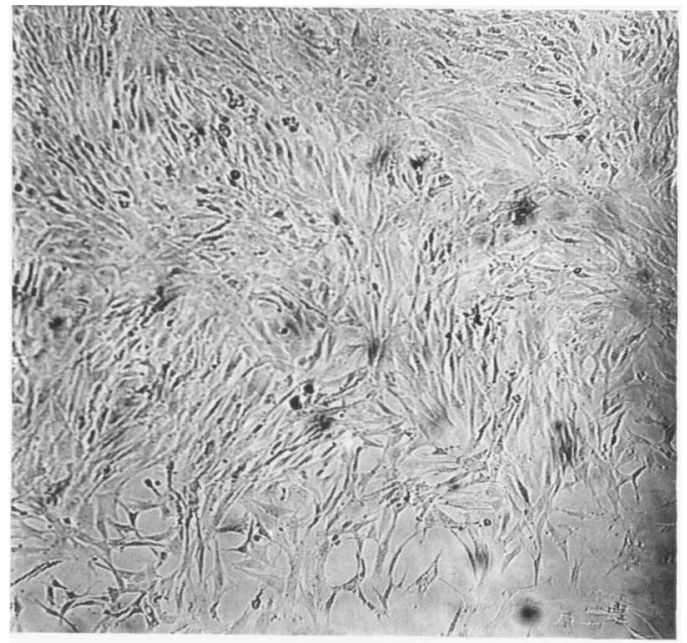

FIG. $4 a$.

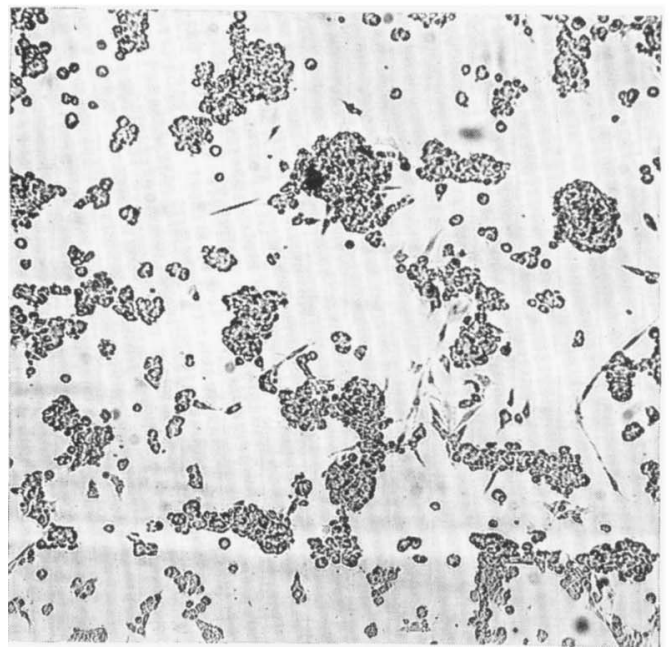

FIG. $4 b$.

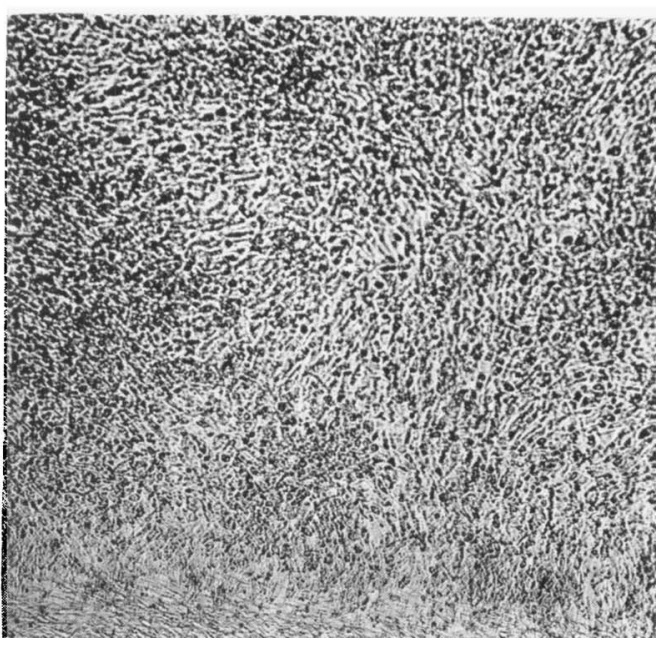

FIG. $4 c$.

FIG. 4.-(a) Control monolayer of chick-embryo fibroblasts.

(b) The cytopathic effect produced by cytopathic factor I (CPF I) of Cl. oedematiens type A.

(c) The cytopathic effect produced by cytopathic factor II (CPF II) of a culture concentrate of $\mathrm{Cl}$. oedematiens type $\mathrm{D}$.

Unstained. $\times 55$. 


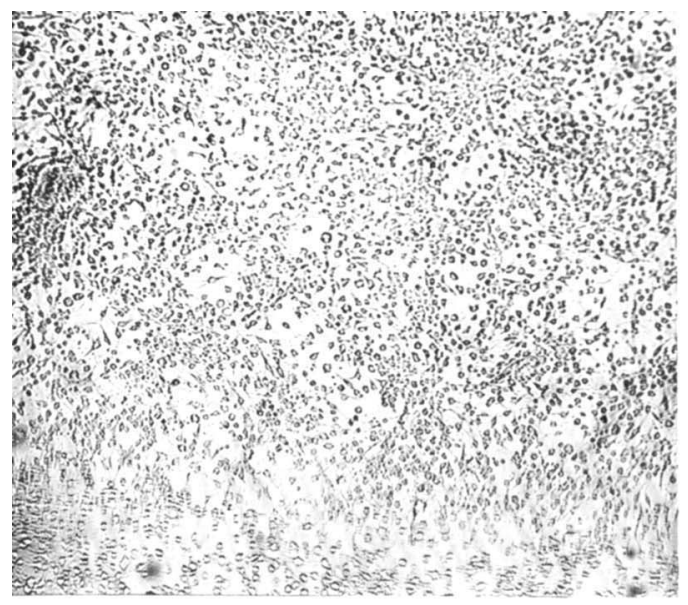

FIG. 5.

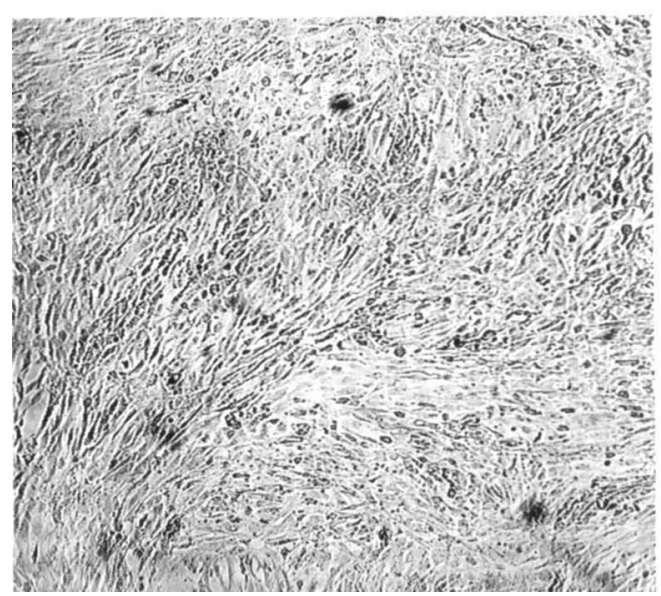

FIG. 7.

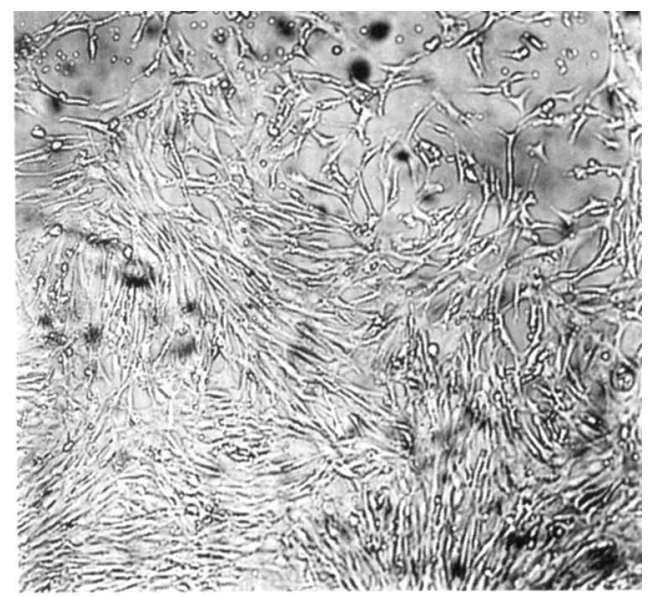

FIG. 6.

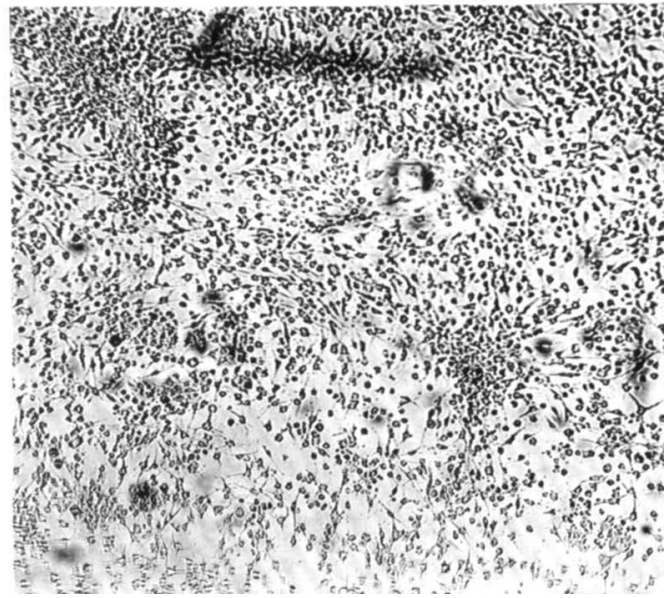

FIG. 8.

FIGs. 5-8.-The cytopathic effect produced by cytopathic factor I (CPF I) in a test dilution of a type-B culture concentrate (fig. 5) is neutralised by a type-A antiserum (fig. 6) and a type-B antiserum (fig. 7), but not by a type-D antiserum (fig. 8 ). $\times 55$. 
frequently do not produce an adequate amount of lecithinase for reliable detection in the LV test system. The LV neutralisation test system is not subject to the effect of a factor produced by type-A strains in CMB that may complicate the haemolysin neutralisation test (q.v.); this haemolytic factor was not detected in our tests when commercially available type-A antiserum was used. If the two neutralisation tests are performed in parallel, a strain of type A or type B is readily distinguished (see, for example, strain 5B in table II which should now be regarded as a type-A strain). Type-D strains typically produce large amounts of the $\beta$-lecithinase and are presumptively identified by the activity of their culture products in the presence of a small amount of $\beta$-antitoxin that is inadequate for neutralisation. If the tests are done with increased amounts of $\beta$-antitoxin, complete neutralisation can be demonstrated (strains 1D, 2D and 9B in table II). Definitive typing of these strains ultimately rests on their lack of production of the $\alpha$-(lethal) antigen and this distinguishes them from type-B strains.

The above results were obtained with stock cultures of laboratory strains. The test systems were then compared by testing 10 freshly isolated strains of $\mathrm{Cl}$. oedematiens obtained from sheep that had died of suspected Black disease. In every case, test material from overnight CMB cultures was sufficiently haemolytic and the 10 isolates were presumptively identified as type-B strains in the haemolysin neutralisation test; only 6 of these 10 strains produced sufficient $\beta$-antigen to give positive LV tube tests. These results confirm that the haemolysin neutralisation test is preferable to the LV neutralisation test for the provisional typing of type-B strains of $\mathrm{Cl}$. oedematiens.

\section{The haemolytic activity of type-A strains}

In CMB medium, type-A strains of $\mathrm{Cl}$. oedematiens produce a haemolytic factor in addition to the $\gamma$-antigen. The additional haemolysin was detected only when the experimental antiserum was used in the neutralisation test (see table II). It was distinct from the $\gamma$-lysin: the haemolytic activity of $0.5 \mathrm{ml}$ of CMB culture supernatants diluted 1 in 2 was not neutralised by 50 anti- $\gamma$ units in neutralisation tests with the experimental antiserum, and a similar volume of undiluted CMB culture supernate was not neutralised by 250 anti- $\gamma$ units of the serum. It was evident that the commercial type-A antiserum neutralised both the $\gamma$-lysin and the non- $\gamma$ component: a volume of the commercial typing antiserum that contained 17 anti- $\gamma$ units completely neutralised the haemolytic activity of $0.5 \mathrm{ml}$ of a 1 in 2 dilution of CMB culture supernatant. Thus, the "non- $\gamma$ " lysin produced a marked effect at low dilutions of CMB culture products. It was detected only in CMB cultures: more potent haemolytic activity in nutrient broth cultures was completely neutralised by 10 anti- $\gamma$ units of either serum in similar tests. The "non- $\gamma$ " lysin in CMB cultures was readily diluted out: the haemolytic activity of a 10-fold dilution of CMB culture supernatant was completely neutralised by 10 anti- $\gamma$ units of experimental antiserum. Thus, the "non- $\gamma$ " haemolytic factor is of low titre and is associated with growth in the presence of meat particles. We were unable to detect an oxygen-labile haemolysin in culture supernatants of $\mathrm{Cl}$. oedematiens 
during the present study, and the relationship of the "non- $\gamma$ " haemolytic factor to the $\delta$-antigen was not determined.

TABLE II

Prompt and delayed results of $H L$ and $L V$ neutralisation tests* with soluble CMB culture products of different types of $\mathrm{Cl}$. oedematiens tested against experimental $\mathrm{Cl}$. oedematiens type-specific antisera

\begin{tabular}{|c|c|c|c|c|c|c|c|c|}
\hline \multirow{4}{*}{$\begin{array}{l}\text { Strain no. and } \\
\text { provisional type of } \\
\text { test organism }\end{array}$} & \multicolumn{8}{|c|}{$\begin{array}{l}\text { Results obtained with culture products of the stated strain } \\
\text { in HL and LV tests }\end{array}$} \\
\hline & \multirow{2}{*}{\multicolumn{2}{|c|}{$\begin{array}{l}\text { without added } \\
\text { antiserum } \\
\text { (positive test } \\
\text { control) }\end{array}$}} & \multicolumn{6}{|c|}{ with a given dose of the stated antiserum } \\
\hline & & & \multicolumn{2}{|c|}{$\begin{array}{c}\text { anti-A } \\
(20 \text { anti- } \gamma \text { units })\end{array}$} & \multicolumn{2}{|c|}{$\begin{array}{l}\text { anti- }-\mathrm{B} \\
\text { (10 anti- } \beta \text { units })\end{array}$} & \multicolumn{2}{|c|}{$\begin{array}{l}\text { anti-D } \\
\text { (109 anti- } \beta \text { units) }\end{array}$} \\
\hline & $\mathrm{HL}^{*}$ & $\mathbf{L V}^{*}$ & HL & LV & $\mathrm{HL}$ & LV & HL & LV \\
\hline $\begin{array}{l}1 \mathrm{~A} \\
2 \mathrm{~A} \\
3 \mathrm{~A} \\
4 \mathrm{~A}\end{array}$ & $\begin{array}{l}+1+11 \\
+1+ \\
+1+ \\
+1+\end{array}$ & $\begin{array}{l}+1+ \\
+1+ \\
-1+ \\
-1+\end{array}$ & $\begin{array}{l}\mathrm{N} / 0 \\
\mathrm{~N} / 0 \\
\mathrm{~N} / 0 \\
\mathrm{~N} / 0\end{array}$ & $\begin{array}{l}\mathbf{N} / \mathbf{N} \\
\mathbf{N} / \mathbf{N} \\
\ldots / N \\
\ldots / N\end{array}$ & $\begin{array}{l}0 / 0 \\
0 / 0 \\
0 / 0 \\
0 / 0\end{array}$ & $\begin{array}{r}0 / 0 \\
0 / 0 \\
\ldots / 0 \\
\ldots / 0\end{array}$ & $\begin{array}{l}0 / 0 \\
0 / 0 \\
0 / 0 \\
0 / 0\end{array}$ & $\begin{array}{r}0 / 0 \\
0 / 0 \\
\ldots / 0 \\
\ldots / 0\end{array}$ \\
\hline $\begin{array}{c}1 \mathrm{~B} \\
2 \mathrm{~B} \\
3 \mathrm{~B} \\
4 \mathrm{~B} \\
5 \mathrm{~B} \dagger \\
7 \mathrm{~B} \\
8 \mathrm{~B} \\
9 \mathrm{~B} \ddagger \\
10 \mathrm{~B} \\
11 \mathrm{~B} \\
12 \mathrm{~B} \\
13 \mathrm{~B}\end{array}$ & $\begin{array}{l}+1+ \\
+1+ \\
+1+ \\
+1+ \\
+1+ \\
+1+ \\
+1+ \\
+1+ \\
+1+ \\
+1+ \\
+1+ \\
+1+\end{array}$ & $\begin{array}{l}-1- \\
-11 \\
+1+ \\
-11 \\
+1+ \\
-1- \\
-1- \\
+1+ \\
-1- \\
11+ \\
-1+ \\
-1-\end{array}$ & $\begin{array}{l}0 / 0 \\
0 / 0 \\
0 / 0 \\
0 / 0 \\
N / 0 \\
0 / 0 \\
0 / 0 \\
0 / 0 \\
0 / 0 \\
0 / 0 \\
0 / 0 \\
0 / 0\end{array}$ & $\begin{array}{c}\ldots / \ldots \\
\ldots / 0 \\
0 / 0 \\
\ldots / 0 \\
\mathrm{~N} / \mathrm{N} \\
\ldots / \ldots \\
\ldots / \ldots \\
0 / 0 \\
\ldots / \ldots \\
0 / 0 \\
\ldots / 0 \\
\ldots / \ldots\end{array}$ & $\begin{array}{c}\mathbf{N} / \mathbf{N} \\
\mathbf{N} / \mathbf{N} \\
\mathbf{N} / \mathbf{N} \\
\mathbf{N} / \mathbf{N} \\
0 / 0 \\
\mathbf{N} / \mathbf{N} \\
\mathbf{N} / \mathbf{N} \\
0 / 0 \\
\mathbf{N} / \mathbf{N} \\
\mathbf{N} / \mathbf{N} \\
\mathbf{N} / \mathbf{N} \\
\mathbf{N} / \mathbf{N}\end{array}$ & $\begin{array}{c}\ldots / \ldots \\
\ldots / \mathrm{N} \\
\mathrm{N} / \mathrm{N} \\
\ldots / \mathrm{N} \\
0 / 0 \\
\ldots / \ldots \\
\ldots / \ldots \\
0 / 0 \\
\ldots / \% \\
\mathrm{~N} / \mathrm{N} \\
\ldots / \mathrm{N} \\
\ldots / \ldots\end{array}$ & $\begin{array}{l}\mathbf{N} / \mathbf{N} \\
\mathbf{N} / \mathbf{N} \\
\mathbf{N} / \mathbf{N} \\
\mathbf{N} / \mathbf{N} \\
0 / 0 \\
\mathbf{N} / \mathbf{N} \\
\mathbf{N} / \mathbf{N} \\
\mathbf{N} / \mathbf{N} \\
\mathbf{N} / \mathbf{N} \\
\mathbf{N} / \mathbf{N} \\
\mathbf{N} / \mathbf{N} \\
\mathbf{N} / \mathbf{N}\end{array}$ & $\begin{array}{c}\ldots / \ldots \\
\ldots / N \\
\mathbf{N} / \mathbf{N} \\
\ldots / N \\
0 / 0 \\
\ldots / \ldots \\
\ldots / \ldots \\
\mathbf{N} / \mathbb{N} \\
\ldots / \ldots \\
\mathbf{N} / \mathbb{N} \\
\ldots / N \\
\ldots / / \ldots\end{array}$ \\
\hline $1 \mathrm{C}$ & $-1-$ & $-1-$ & $\ldots / \ldots$ & $\ldots / \ldots$ & $\ldots / \ldots$ & $\ldots / \ldots$ & $\ldots / \ldots$ & $\ldots / \ldots$ \\
\hline 1D & $\begin{array}{l}+1+ \\
+1+\end{array}$ & $\begin{array}{l}+1+ \\
+1+\end{array}$ & $\begin{array}{l}0 / 0 \\
0 / 0\end{array}$ & $\begin{array}{l}0 / 0 \\
0 / 0\end{array}$ & $\begin{array}{l}0 / 0 \\
0 / 0\end{array}$ & $\begin{array}{l}\mathrm{N} / \mathrm{N} \\
0 / 0\end{array}$ & $\begin{array}{l}\mathbf{N} / \mathbf{N} \\
\mathbf{N} / \mathbf{N}\end{array}$ & $\begin{array}{l}\mathbf{N} / \mathbf{N} \\
\mathbf{N} / \mathbf{N}\end{array}$ \\
\hline
\end{tabular}

$* \mathrm{HL}=$ haemolysin; $\mathrm{LV}=$ lecithovitellin reaction.

The tests were held in the cold before second readings were made (see text).

$+=$ Positive reaction obtained; $\perp=$ weak positive; $-=$ negative reaction; $0=$ no neutralisation; $\mathrm{N}=$ neutralisation; ... = no neutralisation result interpreted when control test gave negative result.

$\dagger$ This strain is now regarded as a type-A strain.

$\$$ This strain may be a type-D strain.

The first reading of each pair is that after incubation at $37^{\circ} \mathrm{C}$, the second that after overnight cooling at $4^{\circ} \mathrm{C}$

\section{The haemolytic activity of the type-C strain}

Culture products of strain GR1C have no recognised biological activity and none was detected in CMB culture supernatants during the present study. 
However, strong haemolytic activity without LV activity was detected in overnight cultures of this strain grown in nutrient broth and in nutrient broth enriched with 5 per cent. of peptone. The haemolytic reaction showed no hotcold effect, and its potency diminished rapidly after storage of the supernatant at $4^{\circ} \mathrm{C}$ and after incubation of the culture for $72 \mathrm{hr}$. These observations were not investigated further in the present study.

\section{Difficulties encountered in the interpretation of serological neutralisation tests}

When the haemolysin and LV neutralisation test systems were used for typing strains of $\mathrm{Cl}$. oedematiens it became clear that the increased sensitivity of the haemolysin test is of further practical value. Antisera that are reputedly type-specific frequently contain small amounts of heterologous antibodies that produce cross-neutralising effects. For example, a $\mathrm{Cl}$. oedematiens type-B antiserum may contain a small amount of anti- $\gamma$ activity that is sufficient to neutralise a type-A strain in a delicately poised neutralisation test system. In the present work, it was found that the LV reaction is more readily neutralised than the haemolysin test by heterologous antisera, and this is presumably attributable to the relative sensitivities of the test systems; clearly, if a sufficient amount of heterologous antiserum is used, the haemolysin neutralisation test is more likely to be vitiated by trace amounts of " unwanted" antitoxins. The problem of cross-neutralisation by heterologous antisera is overcome by diluting the antisera; " unwanted " antibodies are diluted out, but this procedure may give rise to further problems (see Discussion).

\section{An analysis of the factors involved in the $L V$ reaction}

In mixtures of egg-yolk emulsion with culture products of $\mathrm{Cl}$. oedematiens, a positive LV reaction may be attributable to the $\gamma-, \beta-, \epsilon-$ and possibly $\theta$-antigens. In order to differentiate these factors, a thin-layer chromatography procedure based on that described by Scrimgeour et al. was developed in the present study. Concentrated culture products of $\mathrm{Cl}$. oedematiens were incubated with egg-yolk emulsion at $37^{\circ} \mathrm{C}$ for up to $18 \mathrm{hr}$; the lipids were extracted from the reaction mixtures (see Methods) and the lipid products were investigated by thin-layer chromatography (TLC) with silica gel as the stationary phase and various solvents as the mobile phase. Control mixtures of egg-yolk emulsion or culture concentrates were extracted in the above manner, and it was therefore possible to attribute qualitative changes in the lipid components of the reaction mixtures to the action of bacterial enzymes on egg-yolk emulsion. The RF values of some of the lipids varied slightly in different experiments with the same solvent, and most of the lipid components were identified by comparison with standard preparations.

\section{The decomposition of triglycerides by type-A strains}

Egg-yolk emulsion contains substantial amounts of neutral and complex lipids including phospholipids, cholesterol, cholesterol esters, triglycerides, 
diglycerides, free fatty acids and traces of monoglycerides. These constituents are readily resolved by TLC with different solvent systems, and triglycerides are well separated from cholesterol esters and other neutral lipids with cyclohexane:chloroform:acetic acid (50:50:2) as the mobile phase. Triglycerides in egg-yolk emulsion are diminished after 1 hour's incubation with a 1 per cent. solution of lipase (Pancreatin, B.D.H. Ltd, Poole, England), and are replaced by products with reduced RF values. A similar breakdown of triglycerides is obtained after incubating concentrated culture products of type-A strains of

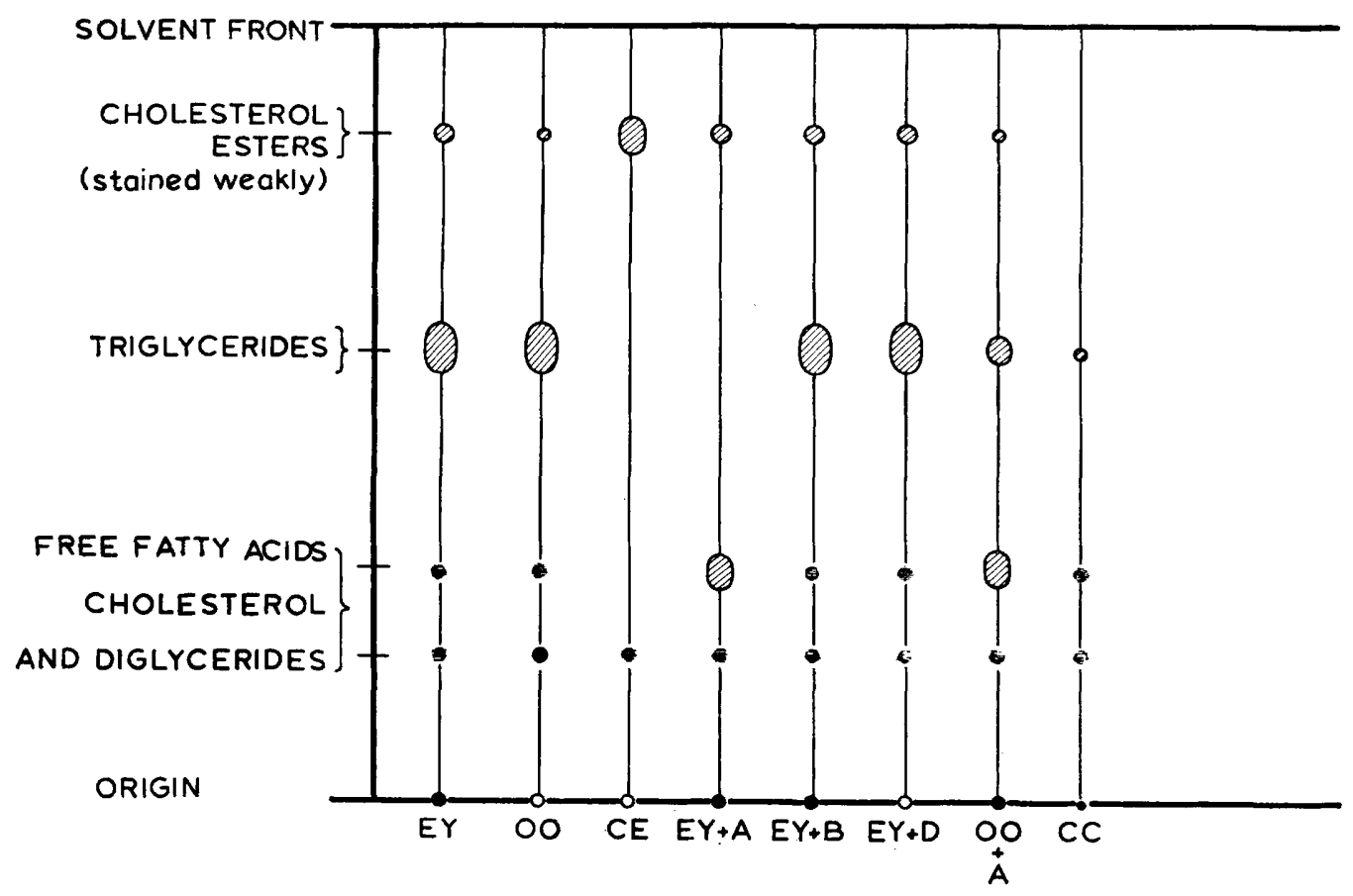

FIG. 1.- Simplified thin-layer chromatography diagram showing the lipid components detected in (i) control samples of egg yolk (EY), olive oil (OO), cholesterol ester (CE), and a culture concentrate (CC), and (ii) reaction mixtures of egg-yolk emulsion or olive oil with concentrated culture products of $\mathrm{Cl}$. oedematiens of the stated types (A, B and D). The mobile phase was cyclohexane:chloroform:acetic acid $(50: 50: 2)$ and the locating agent was iodine vapour. The type-A product has decomposed triglycerides in egg yolk and olive oil; free fatty acids have accumulated.

$\mathrm{Cl}$. oedematiens with egg-yolk emulsion; some culture concentrates were particularly active and produced detectable breakdown of triglycerides within $10 \mathrm{~min}$. at $37^{\circ} \mathrm{C}$; after overnight incubation of these reaction mixtures, triglycerides are absent. The breakdown of triolein in olive oil by type-A strains of $\mathrm{Cl}$. oedematiens was also demonstrated (fig. 1).

In reaction mixtures that were incubated overnight, the substrate triglycerides were replaced by a product with a reduced RF value. Experiments were then done with hexane:diethyl ether:acetic acid $(90: 10: 2)$ as the mobile phase and with standard preparations of free fatty acids as controls; the results suggested that the major product of triglyceride decomposition was free fatty 
acids, and this was confirmed with the "double development" solvent system suggested by Brockerhoff et al. Some free fatty acids were demonstrated in egg-yolk emulsion by this technique, but the amount was considerably increased after incubation of the substrate with type-A concentrates.

In addition to the marked increase in free fatty acids, a slight increase of diglycerides and monoglycerides was detected in tests that were incubated for $1 \mathrm{hr}$; after overnight incubation, only a trace of monoglycerides was present in these reaction mixtures. In the latter experiments, benzene:ether:ethanol: acetic acid $(50: 40: 2: 0 \cdot 2)$ was used as the mobile phase. The above observations are consistent with the presence of lipase activity in culture products of type-A strains of $\mathrm{Cl}$. oedematiens; triglycerides are broken down and free fatty acids are produced by the enzymic activity.

\section{Lack of demonstrable lipase activity in culture products of type- $B$ and type- $D$ strains}

No significant breakdown of triglycerides was detectable after incubating concentrated culture products of strains of types B and D for up to $18 \mathrm{hr}$ with egg-yolk emulsion. Similarly, no significant increase in free fatty acids occurred in these reaction mixtures. Thus, it has not been possible to detect lipase activity in culture products of type-B and type-D strains, although type-A strains are clearly lipolytic.

\section{Demonstration of lecithinase activity}

In all of the solvent systems described above, phospholipids are retained at or near the origin. The different classes of phospholipid can be separated with chloroform:methanol:acetic acid:water $(65: 25: 8: 4)$ as the mobile phase; neutral lipids run with the solvent front in this system.

Lecithin was readily detected in egg-yolk emulsion by thin-layer chromatography, and was identified by comparison with a standard preparation of lecithin. Lecithin was absent after overnight incubation of egg-yolk emulsion with concentrated culture products of strains of $\mathrm{Cl}$. oedematiens of types A, B and $\mathrm{D}$. In reaction mixtures incubated for $1 \mathrm{hr}$, lecithin disappeared after treatment with a type-D concentrate, and was greatly reduced by concentrates of types A and B (fig. 2).

In order to determine the breakdown products of lecithin in the above reaction mixtures, a solvent system consisting of benzene:diethyl ether:ethanol: acetic acid (50:40:2:0.2) was used as the mobile phase. After incubation of egg-yolk emulsion with culture concentrates of strains of types B and D, a new product was consistently present; the new lipid component was distinguishable from the free fatty acids in type-A reaction mixtures incubated for $45 \mathrm{~min}$., but it was no longer detectable in type-A reaction mixtures incubated overnight. The product was not identified by reference to a standard preparation, but its mobility is typical of that exhibited by diglycerides (fig. 3).

The decomposition of lecithin in reaction mixtures with strains of types A, 
$\mathrm{B}$ and $\mathrm{D}$ confirms that a lecithinase enzyme is present in these culture products. The presence of diglycerides in reaction mixtures with strains of types B and D is consistent with lecithinase-C activity, but the results with type-A strains are more difficult to interpret (see Discussion).

The effect of the culture medium on the production of lipase and lecithinases

The results of the present semi-quantitative experiments with concentrates prepared from type-A strains suggested that culture in different media may

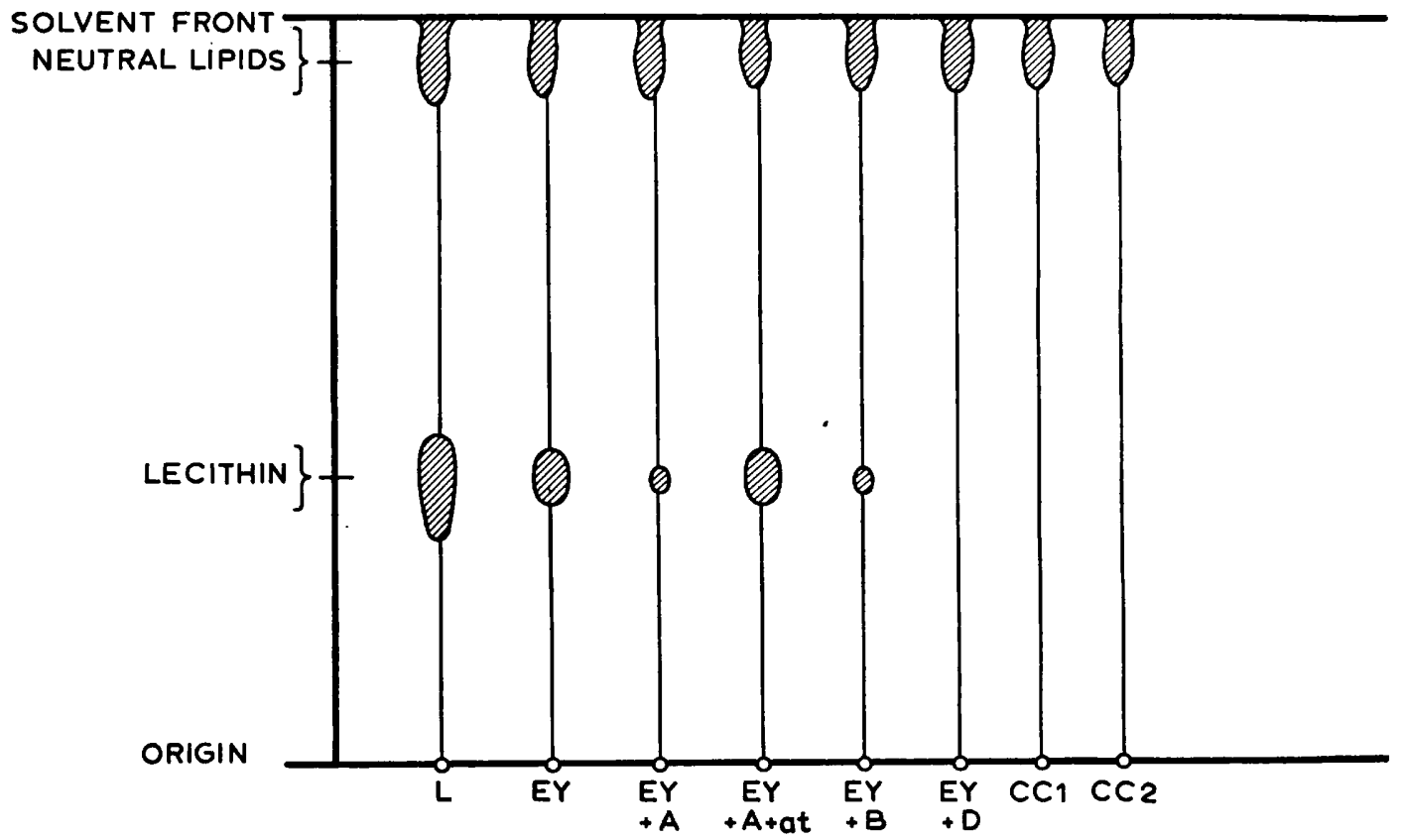

FIG. 2.-Simplified thin-layer chromatography diagram showing the lipid components detected in (i) control samples of lecithin (L), egg yolk (EY) and two culture concentrates (CCl and $\mathrm{CC} 2$ ), and (ii) reaction mixtures of egg-yolk emulsion with concentrated culture products of Cl. oedematiens of the stated types (A, B and D); a type-A reaction mixture with added homologous antitoxin (at) is also included. The mobile phase was chloroform:methanol:acetic acid: water $(65: 25: 8: 4)$ and the locating agent was iodine vapour. All the culture products have decomposed lecithin. The type-A product has been inhibited in this respect by homologous antitoxin.

affect the production of lipase and lecithinase. These enzymic activities were markedly reduced in cultures grown in infusion broth, and it appeared that more lipase was produced in nutrient broth than in CMB. The addition of glucose (1 per cent.) to CMB and nutrient broth seemed to inhibit lipase formation, and lecithinase activity was reduced in media with added glucose.

\section{Serological neutralisation of lecithinase and lipase activities}

The lecithinase activities of strains of types A, B and D were almost completely neutralised by homologous antisera. Significant breakdown of lecithin 
was not detected in reaction mixtures that contained antitoxin, and heterologous antisera failed to neutralise the lecithinase activities; for example, antisera containing anti- $\gamma$ failed to neutralise the breakdown of lecithin by type-B strains. The lipase activity of type-A strains was reduced when homologous antitoxin was present; free fatty acid production was decreased in these reaction mixtures although considerable lipase activity was detectable.

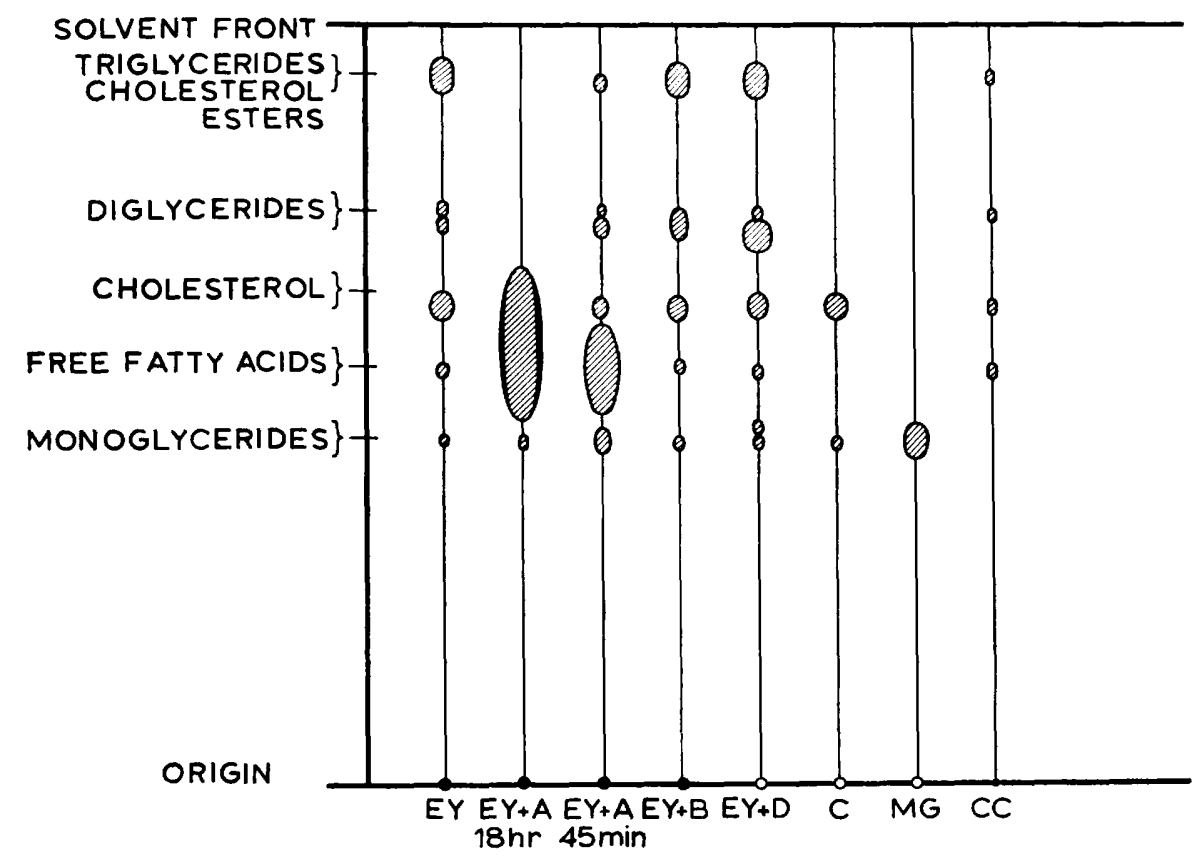

FIG. 3.-Simplified thin-layer chromatography diagram showing the lipid components detected in (i) control samples of egg yolk (EY), cholesterol (C), monoglyceride (MG), and a culture concentrate $(\mathrm{CC})$, and (ii) reaction mixtures of egg-yolk emulsion with concentrated culture products of $\mathrm{Cl}$. oedematiens of the stated types (A, B and D). The mobile phase was benzene:dierhyl ether:ethanol:acetic acid $(50: 40: 2: 0 \cdot 2)$ and the locating agent was iodine vapour. Overnight incubation of the type-A reaction mixture has led to decomposition of triglycerides and diglycerides and accumulation of free fatty acids. At $45 \mathrm{~min}$., a similar reaction mixture shows a diminished triglyceride component with a marked increase in free fatty acids and a slight increase in monoglycerides and diglycerides.

The TLC demonstration of lecithinase neutralisation endorses the interpretation of serological neutralisation tests that involve the LV test system. Further studies are necessary to determine the contribution of lipase activity in some LV reactions, and TLC procedures that detect the products of lecithinase or lipase activity may be of particular value in this respect. A practical problem observed in the above neutralisation tests was that the reaction mixtures that contained antitoxin gave a demonstrable spot on subsequent chromatography; a similar spot was obtained in reaction mixtures with cagsal solution, and the significant common factor may be the cresol and phenol preservatives. 
The soluble lethal factors of $\mathbf{C l}$. oedematiens

Production and stability of the $\alpha$-antigen

The $\alpha$-antigen is produced by strains of types $A$ and $B$, and can be detected by demonstration of lethal activity, which is neutralised by type-A and type-B antisera. In general, cultures of type-A strains contain less lethal activity for mice than cultures of type-B strains. Overnight incubation is sufficient for maximal yields of the $\alpha$-antigen provided that growth is not delayed, and the lethal potency of cultures remained constant during incubation at $37^{\circ} \mathrm{C}$ for 5 days.

Walbum and Reymann (1937) stated that the lethal factor of $\mathrm{Cl}$. oedematiens is inactivated by heating at $50^{\circ} \mathrm{C}$ for $30 \mathrm{~min}$., and that the addition of glucose to the medium markedly reduced the toxin yield. These observations were confirmed during the present study. Walbum and Reymann also noted that the lethal factor is inactivated by precipitation with ammonium sulphate, and has optimum stability at $p \mathrm{H} 6 \cdot 1$. In the present work, the $\alpha$-antigen was precipitated by ammonium sulphate fractionation, and maximum lethal activity was detected in fractions that were 40-60 per cent. saturated with ammonium sulphate; the yield of lethal activity was calculated to be 20 per cent. of that present in the original cultures. In contrast with the results of Walbum and Reymann, the $\alpha$-antigen appeared to be remarkably stable at various $p \mathrm{H}$ values. Concentrated culture products of a type-A strain were held at $p \mathrm{H} 3 \cdot 6,6 \cdot 8$ and $9 \cdot 3$ for $24 \mathrm{hr}$ at $4^{\circ} \mathrm{C}$, and the MLD of each sample was identical in subsequent titrations of lethal activity; the lethal factor was neutralised by appropriate antisera to prove its identity.

The $\alpha$-antigen is non-dialysable, and the MLD of a type-B culture concentrate was increased by at least 8 -fold after 2 hours' exposure at $37^{\circ} \mathrm{C}$ to a $0 \cdot 2$ per cent. solution of trypsin (crystalline trypsin, B.D.H.) in tris-maleate buffer $(p \mathrm{H} 8 \cdot 2,0.05 \mathrm{M})$. The lethal activity of a similar concentrate was toxoided after 18 hours' exposure to 0.064 per cent. of formaldehyde at $37^{\circ} \mathrm{C}$ and 42 hours' exposure to 0.124 per cent. of formaldehyde at $18^{\circ} \mathrm{C}$. The above results suggest that the $\alpha$-antigen is protein or peptide in nature.

\section{The effect of culture products of $\mathrm{Cl}$. oedematiens on tissue-culture cells}

When concentrated culture products of strains of $\mathrm{Cl}$. oedematiens of types $\mathrm{A}, \mathrm{B}$ and $\mathrm{D}$ were added to monolayers of chick-embryo fibroblasts, two distinct cytopathic effects (CPE) were observed (fig. 4): strains of types A and B produced a similar CPE in which the monolayer was disrupted and the fibroblasts became rounded and markedly refractile (cytopathic factor I, CPF I); on the other hand, concentrates prepared from type-D strains produced a different CPE in which the fibroblasts became granular and shrunken with a crenated margin, although the cell sheet remained intact (cytopathic factor II, CPF II). These cytopathic effects are clearly visible after overnight rolling of the test tissue-cultures at $37^{\circ} \mathrm{C}$, but the effect produced by CPF II is more difficult to read and titrate than the obvious effect that is produced by CPF I. 
Cytopathic factor I. It soon became clear that the lethal and CPF I factors of strains of types A and B are closely related. Cultures that were not lethal were not cytopathic; cultures that were heated at $55^{\circ} \mathrm{C}$ for $30 \mathrm{~min}$. lost both lethal and cytopathic activities; and the cytopathic activities of unconcentrated cultures of types A and B were neutralised by either type-A or type-B antisera. The cytopathic effect and examples of neutralisation tests with antitoxic sera are shown in figs. 5-8. Tissue cultures of chick fibroblasts, MK cells and BHK cells are susceptible to CPF I, but chick fibroblasts are the most sensitive. Potent preparations of the cytopathic agent caused a CPE within $2 \mathrm{hr}$ at $37^{\circ} \mathrm{C}$, and 80 per cent. of the cells were affected within $4 \mathrm{hr}$. Chick fibroblasts exposed to CPF I for $5 \mathrm{~min}$., then washed thoroughly, show only a slight CPE subsequently; but washing after exposure for $15 \mathrm{~min}$. does not avoid the development of a marked CPE. The cytopathic factor was neutralised by antiserum added up to $30 \mathrm{~min}$. after addition of the culture products to the tissue-culture cells.

Cytopathic factor II. The cytopathic factor in culture concentrates of type-D strains affects chick fibroblast cells (see fig. 4); products that were lethal in mice were also cytopathic, and both effects were neutralised by an experimental homologous antiserum. In the test systems employed in the present study with $0 \cdot 1 \mathrm{ml}$ as the test dose, unconcentrated cultures of type-D strains were neither lethal nor cytopathic.

\section{The identification of CPF I}

The above results suggest that the lethal and cytopathic activities of strains of types A and B may be attributable to the $\alpha$-antigen. In order to confirm this, it is necessary to demonstrate that both activities are neutralised by different antisera in proportion to the anti- $\alpha$ content of the sera. A concentrated culture product of a type-B strain was used as the test material in these experiments. The intravenous LD50 of the concentrate for mice was estimated by the method of Reed and Muench (1938) to be $0.1 \mathrm{ml}$ of a 1 in 1150 dilution; the 50 per cent. cytopathic dose (CPD50) was similarly estimated to be $0.1 \mathrm{ml}$ of a 1 in 1254 dilution in tests that were read after $24 \mathrm{hr}$. On the basis of these results, the test material was diluted 1 in 12 to provide approximately 100 LD50 or CPD50 for the two test systems in the subsequent neutralisation studies. Accurate dilutions of $\mathrm{Cl}$. oedematiens antisera of types A, B and D were prepared at differences of 20 per cent.; equal volumes of the dilutions of test material and antisera were mixed, and after a neutralisation period of $30 \mathrm{~min}$. at $18^{\circ} \mathrm{C}$, $0.1 \mathrm{ml}$ of each mixture was added to the indicator systems. The results of this experiment are shown in table III.

The type-D antiserum failed to neutralise the lethal and cytopathic effects of the type-B concentrate; the type-B antiserum neutralised both effects at the same dilution of antiserum; the type-A antiserum neutralised both effects with slight discrepancies within 20 per cent. of the same dilution of antiserum. In tests with the type-A antiserum, the CPE was not neutralised in 3 of 4 tissueculture tubes by a dilution of antiserum that suppressed the lethal effect in 
2 of 3 mice. Thus, the lethal and cytopathic effects of a type-B concentrate were neutralised by two separate antisera that had a common anti- $\alpha$ component; both activities were neutralised in parallel by the sera within the limits of experimental error, and the results support the view that the $\alpha$-antigen is responsible for the CPE that we have attributed to CPF I.

TABLE III

Neutralisation of the lethal and cytopathic effects of $\mathrm{Cl}$. oedematiens type $B$

\begin{tabular}{|c|c|c|c|c|c|c|c|}
\hline \multirow{2}{*}{ Test system* } & \multicolumn{7}{|c|}{$\begin{array}{l}\text { Neutralisation obtained with a test-dose of a type-B } \\
\text { concentrate in the presence of type-A antiserum diluted } 1 \text { in }\end{array}$} \\
\hline & 60 & 73 & 89 & 109 & 132 & 156 & \\
\hline Mouse lethality . & $\begin{array}{l}+ \\
+ \\
+\end{array}$ & $\begin{array}{l}+ \\
+ \\
+\end{array}$ & $\begin{array}{l}+ \\
+ \\
+\end{array}$ & $\begin{array}{l}\overline{+} \\
+\end{array}$ & $\begin{array}{l}\overline{-} \\
-\end{array}$ & $\begin{array}{l}- \\
\overline{-}\end{array}$ & \\
\hline \multirow[t]{4}{*}{ CPE with chick fibroblasts } & $\begin{array}{l}+ \\
+ \\
+\end{array}$ & $\begin{array}{l}+ \\
+ \\
+ \\
+\end{array}$ & $\begin{array}{l}+ \\
+ \\
+ \\
+\end{array}$ & $\begin{array}{l}- \\
\frac{-}{+}\end{array}$ & $\begin{array}{l}- \\
- \\
-\end{array}$ & $\begin{array}{l}- \\
- \\
-\end{array}$ & \\
\hline & \multicolumn{7}{|c|}{$\begin{array}{l}\text { Neutralisation obtained with a test-dose of a type-B } \\
\text { concentrate in the presence of }\end{array}$} \\
\hline & \multicolumn{6}{|c|}{ type-B antiserum diluted 1 in } & $\begin{array}{l}\text { type-D } \\
\text { antiserum } \\
\text { diluted } \\
1 \text { in }\end{array}$ \\
\hline & 240 & 294 & 357 & 435 & 503 & 625 & 10 \\
\hline Mouse lethality . & $\begin{array}{l}+ \\
+ \\
+\end{array}$ & $\begin{array}{l}+ \\
+ \\
+\end{array}$ & $\begin{array}{l}+ \\
+ \\
+\end{array}$ & $\begin{array}{l}\overline{-} \\
-\end{array}$ & $\begin{array}{l}\overline{-} \\
-\end{array}$ & $\begin{array}{l}\overline{-} \\
-\end{array}$ & $\begin{array}{l}- \\
-\end{array}$ \\
\hline CPE with chick fibroblasts & $\begin{array}{l}+ \\
+ \\
+ \\
+\end{array}$ & $\begin{array}{l}+ \\
+ \\
+ \\
+\end{array}$ & $\begin{array}{l}+ \\
+ \\
+ \\
+\end{array}$ & $\begin{array}{l}- \\
\overline{-} \\
-\end{array}$ & $\begin{array}{l}- \\
- \\
-\end{array}$ & $\begin{array}{l}\overline{-} \\
\overline{-}\end{array}$ & $\begin{array}{l}- \\
\overline{-} \\
-\end{array}$ \\
\hline
\end{tabular}

* Three mice and 4 tissue-culture tubes were used for each dilution of antiserum. $+=$ Neutralisation; $-=$ no neutralisation.

The type-A antiserum contained 100-150 anti- $\alpha$ units per $\mathrm{ml}, 700-1000$ anti- $\gamma$ units per ml, and $<2$ anti- $\beta$ units per $\mathrm{ml}$. The type-B antiserum contained 510 anti- $\alpha$ units per $\mathrm{ml}$, and 400 anti- $\beta$ units per ml. The type-D antiserum contained $<0 \cdot 1$ anti- $\alpha$ units per $\mathrm{ml}, 4800$ anti- $\beta$ units per ml and $<10$ anti- $\gamma$ units per $\mathrm{ml}$.

\section{Gel-filtration studies}

The identity of CPF I was further investigated in a series of gel-filtration experiments with Sephadex G-200; the details of columns and procedures are 
given previously (see Methods). The results of many fractionations of culture products of types A and B were consistent; lethal activity was detected in

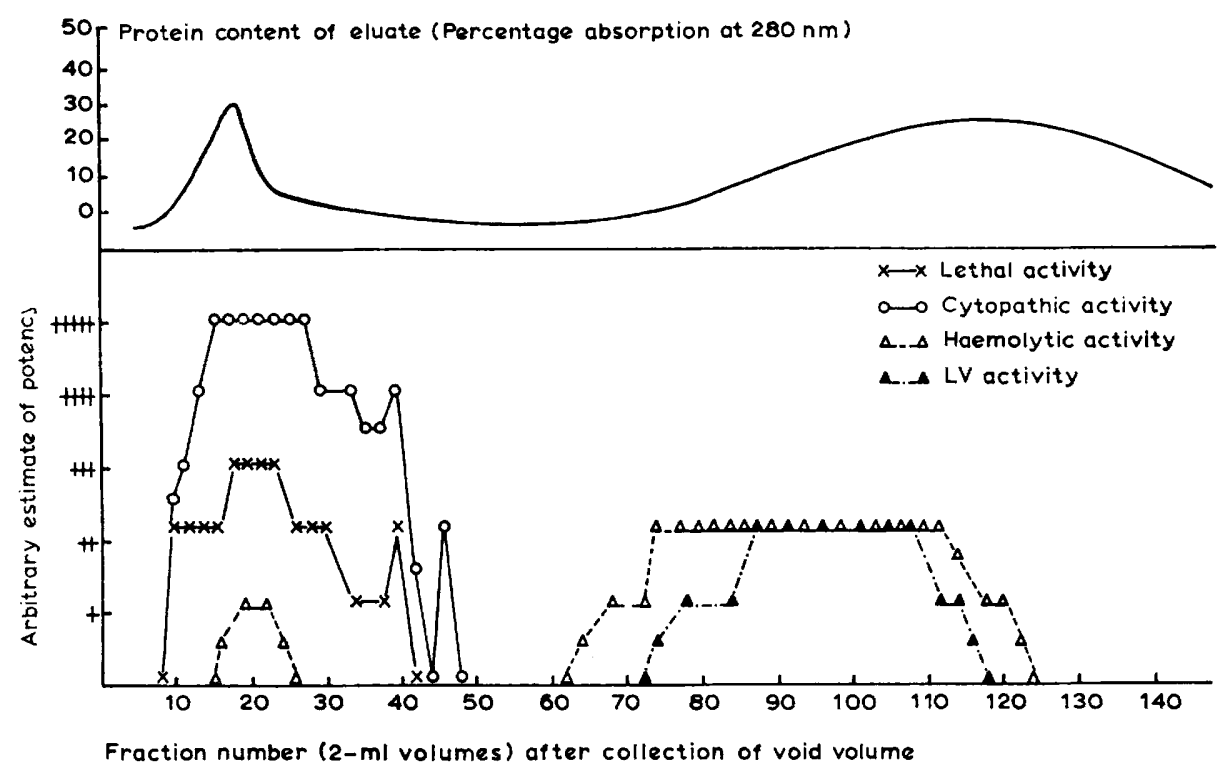

FIG. 9.-Fractionation diagram for concentrated CMB culture products of $\mathrm{Cl}$. oedematiens strain GR2B separated by gel filtration with Sephadex G-200. Fractions containing lethal and cytopathic activities are well separated from fractions containing the major haemolytic and LV factors, but a minor weakly haemolytic component is detectable (see text).

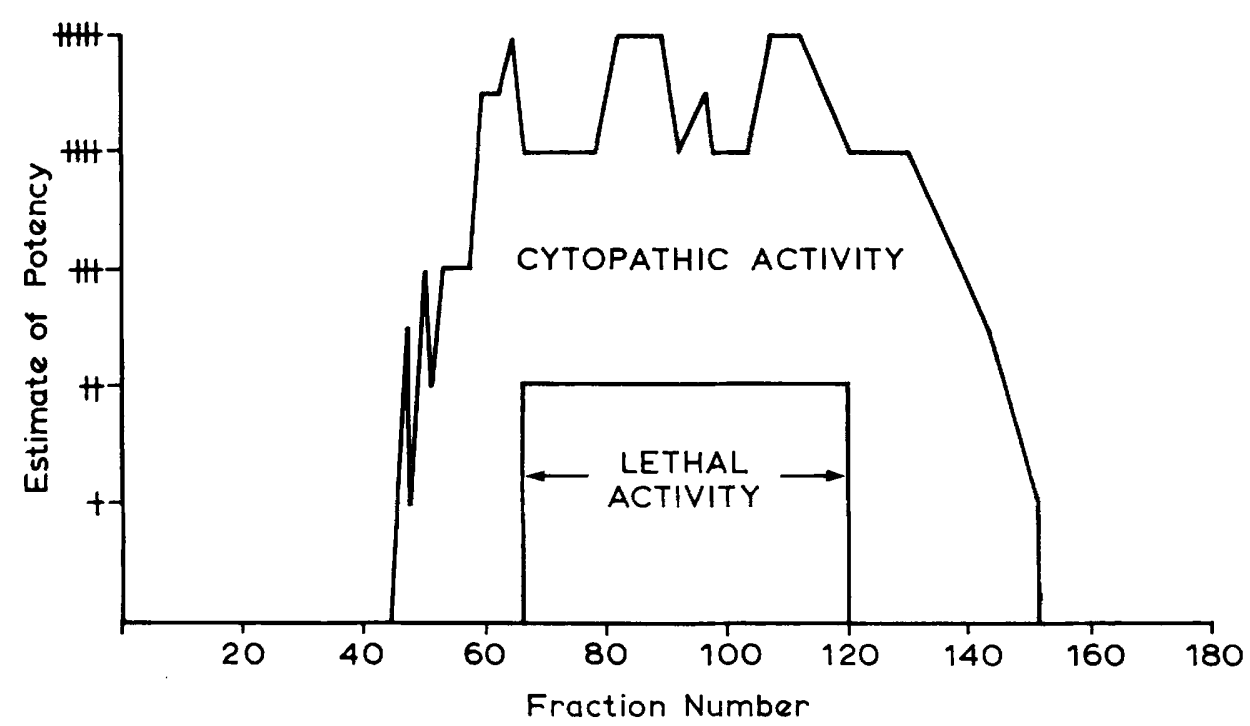

FIG. 10.-Fractionation diagram for concentrated CMB culture products of $\mathrm{Cl}$. oedematiens strain GR1A separated by gel filtration with Sephadex G-200. Fractions containing cytopathic and lethal activities are closely related; these were eluted immediately after the void volume was passed and they contained no haemolysin or lecithinase. 
fractions collected soon after the void volume, and cytopathic activity was closely associated with the same fractions. Both activities were clearly separate from the major haemolytic and LV activities that were located in fractions eluted much later. The results of typical fractionation experiments are given in figs. 9 and 10. The cytopathic activity usually extended beyond the limits of lethal activity, but the sensitivity of the tissue-culture test system appears to be related to the age of the fibroblasts. Similarly, the haemolytic activity extended beyond the limits of LV activity, and this presumably reflects the greater sensitivity of the haemolytic test system. During the fractionation of culture products of type-B strains, a small peak of haemolytic activity was detected consistently in about $10 \mathrm{ml}$ of eluate that contained maximum lethal and cytopathic activities (see Discussion). The results of independent procedures therefore indicate that the lethal and cytopathic activities of $\mathrm{Cl}$. oedematiens of types $\mathrm{A}$ and $\mathrm{B}$ are attributable to the $\alpha$-antigen.

\section{DISCUSSION}

In the present study, the only culture medium that supported consistently good growth of type-B and type-D strains of $\mathrm{Cl}$. oedematiens, with reliably adequate production of the recognised soluble antigens, was cooked-meat broth (CMB). This medium incorporated Oxoid nutrient broth, but the meat particles were prepared in our laboratory (see Methods); commercial preparations of CMB (Oxoid) did not support reliable growth of the exacting type-B and type-D strains. Although our CMB medium gave satisfactory results, the limitations of the available typing procedures should be appreciated. Before the $\mathrm{Cl}$. oedematiens group was subclassified on the basis of soluble antigens, a haemolysin neutralisation test was developed by Hayward and Gray (1946) for the differentiation of $\mathrm{Cl}$. oedematiens and $\mathrm{Cl}$. septicum. The results showed that differences existed within the $\mathrm{Cl}$. oedematiens group and some of the differences are now readily explained by reference to the known soluble haemolysins of type-A and type-B strains. A complication was that type-A strains grown in CMB medium produced a haemolytic reaction that was not neutralised by homologous antisera. The work of Oakley et al. (1947) in the subsequent year focused attention on the LV reaction, but the present work has shown that this reaction alone is not adequate for typing purposes. For example, unconcentrated $\mathrm{CMB}$ cultures of type-B strains frequently contain insufficient amounts of the $\beta$-antigen, a haemolytic lecithinase, to give a positive LV reaction; on the other hand, the amount of $\beta$-antigen in type-B cultures is sufficient to ensure consistently positive reactions in haemolysin tests with human red cells which are considerably more sensitive than the red cells of horse and sheep to the haemolytic products of $\mathrm{Cl}$. oedematiens.

The haemolysin neutralisation test gave meaningful results with strains of all types of $\mathrm{Cl}$. oedematiens in the present study, but it became clear that the haemolysin and LV test systems are delicately poised as, on occasion, haemolytic and LV effects were not reliably neutralised by homologous antisera if the testing procedure was altered. The haemolytic and LV activities of strains of types $\mathrm{A}$ and $\mathrm{D}$ are not completely neutralisable if the organisms are grown in 
the presence of added fermentable carbohydrate. Moreover, tests with an experimental homologous antiserum confirmed that a minor haemolytic factor is present in CMB cultures of type-A strains. The commercially available serum neutralised this additional factor and it would not normally be detected in routine typing procedures. We find it advisable to perform haemolysin and LV neutralisation tests in parallel and this usually gives definite results. Nevertheless, a frequent problem in these haemolysin and LV neutralisation tests is cross-neutralisation by heterologous antisera. These effects are presumably attributable to traces of non-type-specific antibodies in the antisera which then require to be diluted to exclude the unwanted activity. Manipulation of serological neutralisation in this way is not satisfactory and a typing procedure that demands such a step is unlikely to gain wide acceptance. An obvious danger is that antibodies to the minor type-specific soluble antigens may be diluted out along with the unwanted effects, with consequent failure of important neutralisation mechanisms in the test systems.

Antisera that are used for typing should be reliably type-specific, and their development depends upon knowledge of all of the soluble antigens of the organism that may participate in the test reactions. Cl. oedematiens produces a confusing array of haemolysins, haemolytic lecithinases (which should now be called phospholipases), and lipases, but recent advances in thin-layer chromatographic techniques for the investigation of lipid complexes now facilitate differentiation of factors that affect egg-yolk emulsion. The procedures developed during the present study were based on those described by Scrimgeour et al. (1967) who used chloroform:acetic acid (95:5) as the mobile phase; we were unable to separate mixtures of simple and complex lipids with a single solvent system and we used a number of mobile phases with different polarities in order to identify the significant lipid components.

Lipase and lecithinase activities were clearly detectable in reaction mixtures of type-A culture products with egg-yolk emulsion: triglycerides and lecithin in the emulsion were broken down and the lipid product of these activities was free fatty acids. Slight increases of diglycerides and monoglycerides were detected in reaction mixtures incubated for $1 \mathrm{hr}$, but only a trace of monoglycerides was present after overnight incubation of the test mixtures. Diglycerides and monoglycerides are intermediate products in the lipolytic reaction, but diglycerides are also formed by the action of the $\gamma$-antigen on lecithin. Thus, diglycerides may be released from egg-yolk by the lecithinase and the lipase activities of type-A strains and the combined enzymic activities account for the production of free fatty acids from lecithin and triglyceride substrates: triglycerides are broken down by lipase activity to free fatty acids through pathways that involve diglyceride and monoglyceride stages; lecithin is hydrolysed by lecithinase- $\mathrm{C}$ to diglycerides and phosphoryl choline, and the diglycerides are subsequently hydrolysed by lipase activity through monoglycerides to free fatty acids.

A different pattern of results was observed in reaction mixtures of egg-yolk emulsion with strains of types B and D; lecithin is broken down by these strains and culture concentrates of type-D strains are particularly potent in 
this respect. A product with a mobility that is characteristic of diglycerides was regularly present in chromatograms of these test mixtures, and the diglycerides appear to be the more slowly moving 1-2 diglyceride component and not 1-3 diglycerides. We found no evidence of true lipase activity in culture products of type-B and type-D strains that were incubated with egg-yolk emulsion for up to $20 \mathrm{hr}$. Triglyceride substrate that is present or added is not demonstrably affected; diglycerides that result from the lecithinase-C activity of the $\beta$-antigen are not decomposed, and although a slight but significant increase in spots in the monoglyceride area is occasionally detected in these reaction mixtures, we have been unable to demonstrate a significant increase in free fatty acids if account is taken of the free fatty acids that are present in the culture controls. The results are consistent with the presence of a lecithinase-C enzyme that hydrolyses lecithin to 1-2 diglycerides and phosphoryl choline, but our present semi-quantitative TLC procedure has not confirmed that demonstrable lipase activity exists in culture products of type-B and type-D strains.

The haemolysin and LV tests and the thin-layer chromatographic procedures are clearly of value in differentiating the $\beta$-, $\gamma$ - and $\epsilon$-antigens, but demonstration of the production of the lethal $\alpha$-antigen is necessary to distinguish type-B strains from type-D strains. The $\alpha$-antigen is a most interesting product. It has formidable toxicity for the experimental animal and a tissue-culture technique developed in the present investigation provides in-vitro evidence of the cytopathic potential of the $\alpha$-antigen. A well-defined cytopathic effect is demonstrable with tissue cultures of chick embryo fibroblasts and our results indicate that the cytopathogenicity test provides a more sensitive index than the mouse-lethality tests for the assay of the $\alpha$-toxin. However, the age and number of the fibroblasts appear to have a marked influence on the sensitivity of the tissue-culture test system.

Slight differences between the doses of type-A antiserum required to neutralise the lethal and cytopathic activities of type-B cultures (see table III) may be related to the presence of hyaluronidase in type-B culture products (Keppie, 1944); this enzyme might enhance the development of the cytopathic effect of the $\alpha$-antigen in vitro. Hyaluronidase is not produced by type-A strains and anti-hyaluronidase is therefore likely to be absent from type-A antisera.

Type-D strains do not produce the $\alpha$-antigen, and the cytopathic effect (CPE) of concentrated type-D culture products can be readily distinguished from the effect of the $\alpha$-antigen described above. The CPE of type-D culture concentrates is correlated with their lethal activity and both effects depend upon the presence of large amounts of the $\beta$-antigen. Accordingly, it is more difficult to demonstrate these effects with unconcentrated culture products.

The results of our gel-filtration studies indicate that the $\alpha$-antigen can be separated from the $\beta$ - and $\gamma$-antigens on columns of Sephadex G-200. Phillips and Batty (1963) reported separation of the $\alpha$-antigen from an amylase present in the starting material; these workers used Sephadex G-100 and the resolution of other biological activities was not reported. In the present study, the 
$\alpha$-antigen was well separated from the major haemolytic and LV factors in culture products of strains of types A and B; however, in experiments with type-B strains, haemolytic activity was demonstrated in some of the fractions that contained maximum lethal $(\alpha)$ activity. This may be attributable to fractionation of a purely haemolytic component such as the $\zeta$-antigen (Oakley et al.), or it may represent a minor lecithinase component eluted in association with the $\alpha$-antigen and detectable only with the more sensitive haemolytic test system. The results confirm that it is possible to prepare relatively stable semipurified preparations of the $\alpha$-antigen, and preliminary work with toxoided preparations (Rutter, 1968) showed that they produced protective antisera in rabbits.

The present system of typing $\mathrm{Cl}$. oedematiens, based on the demonstration of the $\alpha-, \beta$ - and $\gamma$-antigens in culture products, has been usefully applied as follows in the present investigation: the unconcentrated supernatant of a pure culture of the test strain grown overnight anaerobically in CMB medium at $37^{\circ} \mathrm{C}$ was subjected to haemolysin and LV neutralisation tests with type-A and type-B antisera (see Methods). It is not possible to devise a meaningful neutralisation test system without detailed knowledge of the antitoxin content of the typing antisera and this information is not supplied with the commercially available sera. At present, two points merit particular attention: (i) the actual amount of $\beta$-antitoxin is important because a fairly reliable initial distinction may be drawn between type-B and type-D cultures on a quantitative basis with respect to $\beta$-antigen, and (ii) if dilution is necessary to exclude cross-reacting antibodies, the type-specific antitoxins must be present in adequate amount to retain complete neutralising activity at their final dilution in the test system.

Type-A strains are clearly differentiated in the present procedure from a type-C strain, which gives negative results in the haemolysin and LV tests, and from type-B and type-D strains which give different neutralisation patterns. It may be possible to differentiate strains of types $B$ and $D$ in neutralisation tests with 10 and 100 anti- $\beta$ units, as the haemolytic and LV activities of type-D cultures are typically not neutralised in the presence of 10 anti- $\beta$ units. On some occasions, however, neutralisation occurs at the lower level and the final differentiation between strains of types B and D depends on the demonstration of the $\alpha$-antigen in type-B cultures. The production of the $\alpha$-antigen by typeA strains should also be confirmed. Tests that demonstrate the $\alpha$-antigen include mouse-lethality tests, dermonecrotic tests and the cytopathic test that we have described; in practice the choice is influenced by the facilities of the laboratory and the experience of the individual. We have been impressed with the definition and sensitivity of the cytopathic test when good cell sheets of young fibroblasts are used. On the other hand, we have particularly appreciated the reliability of the mouse-lethality test when tissue-culture troubles have arisen.

The present findings endorse many of the observations and deductions made by Oakley and his colleagues in their remarkable serological analyses of the soluble antigens of $\mathrm{Cl}$. oedematiens. The development of a haemolysin 
neutralisation test with human red cells in the present study provides a valuable addition to the typing procedure devised by Oakley et al., and it is likely that thin-layer chromatography will shed further light on the complex interactions of the lecithinases (phospholipases) and lipolytic enzymes. The most intriguing problems that remain concern the nature and mode of action of the lethal $\alpha$-antigen; the methods of purification and in-vitro demonstration that we describe may facilitate its further characterisation.

\section{SUMMARY}

Problems associated with the use of the lecithovitellin (LV) reaction for typing strains of Clostridium oedematiens have been defined and investigated. The haemolysins of the various types of the organism were studied with particular reference to their application to serological neutralisation tests. A haemolysin (HL) neutralisation test has been developed with human red cells as the substrate; the test is recommended for use in parallel with the LV test system in typing procedures. The HL test is more sensitive than the LV test and is of particular value in identifying type-B strains, which frequently produce inadequate amounts of the $\beta$-antigen for detection in LV tests with unconcentrated culture products.

Thin-layer chromatographic procedures have been applied and extended to differentiate the various soluble products of $\mathrm{Cl}$. oedematiens that contribute to $\mathrm{LV}$ activity in culture concentrates. It was confirmed that strains of types A, $\mathrm{B}$ and $\mathrm{D}$ consistently decompose lecithin; type-D strains are particularly active in this respect. Potent lipolytic activity was demonstrable in culture products of type-A strains. The lipolytic activity of these strains releases free fatty acids from triglyceride substrates in egg yolk and from the diglyceride products of lecithinase-C (phospholipase-C) activity. Diglycerides accumulate in reaction mixtures of type-B and type-D strains, which do not appear to produce a lipase.

The production, stability and partial purification of the lethal $\alpha$-toxin were studied. A cytopathic factor (CPF I) in culture products of $\mathrm{Cl}$. oedematiens of types $\mathrm{A}$ and $\mathrm{B}$ is almost certainly the $\alpha$-antigen. In concentrated preparations of type-D cultures which contain high concentrations of $\beta$-antigen, a separate cytopathic effect was demonstrable. The cytopathogenicity test with CPF I provides a convenient in-vitro assay procedure for the $\alpha$-antigen.

We are greatly indebted to the Horserace Betting Levy Board for a Research Training Scholarship awarded to Dr J. M. Rutter to begin the investigation. These studies were further generously supported by the Agricultural Research Council (Grant AG 15/57); we acknowledge their continued support and the kind encouragement given to us by $\operatorname{Dr} R$. H. A. Swain. We are particularly indebted to Dr G. S. Boyd and his colleagues for assistance with the biochemical problems, and to Dr Isabel W. Smith and Dr J. F. Peutherer for their help in the development of the cytopathogenicity test. It is a pleasure to record our thanks to Dr G. Harriet Warrack, Mr H. B. G. Epps (Wellcome Research Laboratories), Mr J. R. Hepple, Dr R. A. Cumming (Director of our Regional Blood Transfusion Service) and Miss Elizabeth Fowler for materials and assistance given at various stages of the study. 


\section{REFERENCES}

Brockerhoff, H., Hoyle, R. J., AND 1966. Canad. J. Biochem., 44, 1519. HuANG, P. C.

Brooks, M. Elizabeth, Sterne, M., and 1957. J. Path. Bact., 74, 185. WARRACK, G. HARRIET

Cruickshank, R.

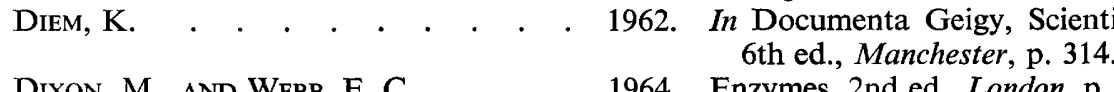

1965. Medical microbiology, 11th ed., Edinburgh and London.

Dixon, M., AND WebB, E. C. . . . . 1964. Enzymes, 2nd ed., London, p. 39.

Dulbecco, R. . . . . . . . . 1952. Proc. Natn. Acad. Sci. U.S.A., 38, 747.

Freeman, C. P., AND West, D. . . . . 1966. J. Lipid Res., 7, 324.

Gadalla, M. S. A. . . . . . . 1965. Ph.D. Thesis, Univ. Edinburgh.

Ha Yward, NanCy J., AND Gray, J. A. B. 1946. J. Path. Bact., 58, 11.

JAMIESON, S.

1949. Ibid., 61, 389.

KEPPIE, J.

1944. Ph.D. Thesis, Univ. Cambridge.

Macfarlane, MarJorie G. . . . . 1948. Biochem. J., 42, 590.

" . . . . . 1950. Ibid., 47, 267.

MACPHERSON, I., AND STOKER, M.

1962. Virology, 16, 147.

MANGOLD, H. K

1965. In Thin-layer chromatography, ed. by E. Stahl, New York and London, p. 149.

MoORe, W. B.

1968. J. Gen. Microbiol., 53, 415.

Nichols, B. W.

1964. In New biochemical separations, ed. by A. T. James and L. J. Morris, London, p. 332.

OAKLey, C. L., AND Warrack, G. 1959. J. Path. Bact., 63, 45. HARRIET

OAKley, C. L., Warrack, G. Harriet, 1947. J. Gen. Microbiol., 1, 91. and Clarke, Patricia H.

Phillips, A. W., ANd Batty, Irene . 1963. Nature, Lond., 198, 1200.

ReEd, G. B., AND OrR, J. H. . . . . 1941. War Med., Chicago, 1, 493.

Reed, L. J., ANd Muench, H. . . . 1938. Amer. J. Hyg., 27, 493.

RutTer, J. M. . . . . . . . . . . 1968. Ph.D. Thesis, Univ. Edinburgh.

Scrimgeour, G., Keane, P. M., AND 1967. J. Path. Bact., 93, 688. ALDER, V. G.

Sheldon, D. R., Moskowitz, M., AND 1959. J. Bact., 77, 375. DEVERELL, M. W.

SMITH, L. DS.

Veto, I., BaCkhausz, R., AND HoRvath, I.

Walbum, L. E., and Reymann, G. C. . WALDI, D.

1955. Introduction to the pathogenic anaerobes, Chicago.

1957. Proc. III Int. Meet. Biol. Standardn (Opatija, Jugoslavia), p. 33.

1937. J. Path. Bact., 44, 379.

1965. In Thin-layer chromatography, ed. by

E. Stahl, New York and London, p. 255.

Willis, A. T., AND HobBs, G.

1958. J. Path. Bact., 75, 299.

ZeMSKOV, E. M.

1964. Fedn Proc. (Transl. Suppl.), 23, 85. 